\title{
Reflexivity, Validity and Roses
}

\author{
LORELEI NEWTON \\ University of Victoria (Canada)
}

My intent here is to explore the relationship between the concepts of validity and reflexivity. Recognizing the long-standing debate over what constitutes validity (e.g., Angen, 2000) and how these conceptualizations influence/interact/interfere with reflexivity, it is not my goal to define these two concepts from any particular theoretical perspective but instead to "develop an understanding of the range of [their] use" and to become clearer about my understandings as a result (Griffith, cited in Cheek \& Gough, 2005 , p. 302). Quite contrary to other scholarly papers I have authored, I do not enter this endeavor with a specific thesis or argument; rather, in the spirit of complex thinking I attempt a "layering that bring(s) forth depth and creation of new meaning" (Doll, 2008, p. 74). My intent is to juxtapose representations of validity and reflexivity as having unambiguous meanings with other possible meanings and to see how this plays out. That is, rejecting the notion that these concepts represent a dichotomy, I explore the intertwined meanings from three paradigms significantly influencing my research (feminism, poststructuralist and positivism) to see what possibilities of meaning may emerge from this "third space" (Doll, 2008). As I am a registered nurse, this exploration takes place in the context of healthcare research, where the stated focus of research is the patient and/or improving patient care. Currently, the majority of healthcare related decisions are grounded in valid quantitative evidence.

In the quantitative research tradition, validity represents the capacity of a particular statistical test to measure that which it is claims to be able to measure (Salkind, 2004). Validity is vital to quantitative research because only valid results can be interpreted and generalized (e.g. Rothman, Greenland, \& Lash, 2008). Although there are various classifications of quantitative validity (e.g., Salkind), all sub-types reflect that aspect of research to which such standards will be applied and the underlying assumption 
remains the same: That the research tool used can accurately measure an isolated acontextual portion of research and that claims can be made in a direct causal fashion regarding the extent to which this can be done. Because of the emphasis on the validity imperative of assessing the worth of (quantitative) research, the notion of validity has become a central feature to debates of how to evaluate quality of research outside the quantitative realm.

Sometimes these debates seem to contribute to the dichotomizing of qualitative/ quantitative research by contrasting qualitative meanings of validity with those used in quantitative research (e.g. Mahoney \& Goertz, 2004). Other researchers discuss validity in generic terms (e.g. Jackson \& Gillis, 2002) or consider that the specific research tradition should instead determine how validity would be assessed (e.g., Lather, 2001). In addition, validity is said to represent epistemological differences amongst researchers about what is valid research (or not), regardless of the method/methodologies used (Scheurich, cited in Freeman, de Marrais, Preissie, Roulston, \& St. Pierre, 2007). Complexity theory further complicates validity from both quantitative and qualitative perspectives. Since "input does not equal output" (Trueit, 2008, p. 36), there is no underlying assumption that an obvious, linear research progress will dominate any evaluation of validity. The reconsideration of validity from non-quantitative perspectives brings into question the ability of the researcher to be neutral and separate from how meaning is constructed during the research process. Thus, the interplay of validity and reflexivity seems to be an important aspect to consider in terms of my own research.

The use of reflexivity in social sciences seems to most often focus on the selfreflexivity of the researcher (Munhall, 2007). It is grounded in the epistemological belief that it is impossible for the researcher to remain external or apart from that which is being researched (Angen, 2000). The purpose of reflexivity can be described as the exploration of the "ways in which a researcher's involvement with a particular study influences, acts upon and informs such research" (Nightingale \& Cromby, 1999, p. 228). That is, a professional and personal recognition that the researcher is contributing to the construction of meaning while engaged in research (Munhall). This seems to imply a causal relationship between how the researcher constructs meaning and the researcher's own research process. In this way, I wonder: Do qualitative researchers use their own lived experiences to construct measures of validity? Thus, the emphasis placed on the value of either validity and/or reflexivity influences how each is taken up by the researcher.

Those who value the quantitative conceptualization of validity usually have a traditional view of science, underpinned by a positivist ${ }^{1}$ philosophy. From this perspective, self-reflexivity constitutes subjective opinion (Angen, 2000) that represents a problem to be eradicated with proper research design. Influences from outside of a contained research project that might interfere with validity are referred to as threats (Somekh \& Lewin, 2005). Because many threats to a quantitative research project exist,

\footnotetext{
${ }^{1}$ Positivism is a philosophical theory that claims knowledge can only be gained through direct observation from sense experience (Mautner, 2005; Rodgers, 2005).
} 
there are multiple checkpoints constructed along a presented linear progression of the research to assist the vigilant researcher. The term validity implies "the quality of being valid in law, legal authority, force and strength...the quality of being well founded in fact, or established on sound principles" (OED, 2009). Perhaps the biggest threat to validity claims based in the dominant discourse of "real" science is the challenge to the existence of an objective truth as well as to the belief that "science can be neat and tidy" with concrete answers to solve difficult problems instead of "embedded in the messiness of life" (William Doll, personal communication, January 12, 2009).

Those who value reflexivity often reject the traditional meaning of validity because, as social constructivists, they do not subscribe to the idea that an objective reality exists external to their research (e.g. Angen, 2000). In addition, these researchers also contend that multiple realities exist (e.g. Whittemore, Chase, \& Mandle, 2001). As such, claims that judge constructions such as research findings, as being inherently true or false, just do not make sense. Reflexivity is highly valued and central to many researchers' examination of their own subjectivity and impact of that on the research process, especially analysis and interpretation (Somekh \& Lewin, 2005). Influences that interfere with reflexivity of the researcher, instead of being viewed as threats, may indeed be viewed as opportunities or possibilities to provide insight into the practice of doing research. Or perhaps these threats represent avenues for qualitative research to merely emulate the status quo instead of challenging it. Is challenging the status quo always the goal of the reflexive researcher?

In reviewing the literature, I am fascinated by how this debate has somehow moved from considering the transparency of measurement to the quality, or even actual worth of various research approaches. In contemporary healthcare research, quantitative research methods are considered the gold standard. Validity is key from this perspective. Because patients and their safety represent such an important priority, proponents of exclusive reliance on quantitative methods contend that only findings (i.e. evidence) from high quality and rigorous research (i.e. quantitatively valid) should be included in healthcare practitioner guidelines (Shojania, Duncan, McDonald, \& Wachter, 2002). Further to this, it has been put forth that basing practice guidelines on nonevidence is contrary to competent and professional practice (Shojania, Duncan, McDonald, \& Wachter). In this way, other forms of research are often dismissed, having too many validity threats to be incorporated into practice guidelines. Politics and ethics are not considered in this process. But most significantly, at this site patient perspectives are almost nonexistent. Yet, isn't the view of the patient, the ethics of moving research findings into practice and the political implications/influences of this process central to validity regardless of the tradition of research one is situated within? Can we know "that which we intended to measure" was actually "what was measured" without confirmation from patients and/or their families? Stronach and MacLure (1997) urge me to keep in mind the traditional views of concepts such as validity and reflexivity instead of rejecting them. This will draw attention to the relationship between the concepts and "resist closure...to find an opening in discourses, regimes, policies, theories or practices which tend to the inertia of closure and certainty" (Stronach \& MacLure, p. 6). To this 
end, instead of turning to traditional and academically acceptable literature to further explore the relationship between validity and reflexivity, my starting point for new considerations of possible openings will begin with an excerpt from a rap song by the artist Kayne West entitled Roses (for Grandma):

"I know it's past visitin' hours

But can I please give her these flowers?

The doctor don't wanna take procedures

He claimed her heart can't take the anesthesia

It'll send her body into a seizure

The little thing by the hospital bed, it'll stop beepin'

Hey chick, I'm at a loss for words

What do you say at this time?...

I asked the nurse, "Did you do the research?"

She ask me, "Can you sign some T-shirts?"...

Like outside of the emergency room, room

You can feel my heart beat, beat, beat

If she pull through, we gon' find out soon

But right now she's sleep, sleep, sleep

My mama say, they say, "She could pass away any day"

Hey chick, what these doctors know anyway?

Let me see the X-Rays, I ain't no expert, I'm just hurt

Cousin Kim took off for work

Plus my aunt Shirley, aunt Beverly

Aunt Claire and aunt Jean

So many aunties, we have an auntie team...

When they said that she made it

Did you see the eyes gleam?

I think we at a all time high

To get there we run, we fly, we drive

'Cause with my family we know where home is

So instead of sendin' flowers, we the roses..." (West, 2005)

In the culture of nursing and healthcare, patients' families are often viewed as "intruders" not roses:

I know what it is like to be a rose: My sister was widowed while she was pregnant. I was her labor support. She had complications that required an emergency C-section. The nurses, my beloved profession, did not allow me into the operating room. While pacing the hall, trying to decide what to do, I was called into the operating room by the obstetrician, concerned about the well being of her patient. As I entered the room, I saw 
the circulating nurse trying to force an oxygen mask onto my sister's face as she was pushing it away, calling for me. I took her hand and whispered, "Donna, its' going to be okay. We are finally going to meet your baby!" I watched as her vital signs (blood pressure, heart rate, oxygen saturation) dramatically settled to a safe range.

I know roses are important but I also know what its like to try to increase oxygenation to a compromised fetus of an uncooperative mother while feeling the dread of potential serious harm witnessed before. I also know what it is like to try to create calm in a storm of family chaos surrounding a dying patient. Why does that matter?

From a feminist perspective, the importance of reflecting on the rap song and my own experiences of being the family member of a seriously ill patient cannot be underestimated. Explicating my positionality and situatedness within a research endeavor hinges on such personal insights. I (we) owe a huge debt to feminist philosophers who, through processes of reflexivity in feminist methodologies, have pushed the bounds of "what we know" and "how we are known", and brought to the fore the contested and situated nature of knowledge (e.g. Burns \& Walker, 2005). In my own data collection, my research journal plays a central role for this purpose. The more transparent I can be about my values and assumptions as a woman/mother/wife/ nurse/fill-in-the-blank, the more valid my research will be deemed.

From a post structural perspective, there are many areas to trouble my reflexivity. Which of my "selves" am I reflexive about? I must recognize that there are severe limits to my ability to "self-critique" (Lenzo, 1995), especially when there are so many of me. Language at the knowledge/power nexus can never be transparent (Gillen \& Petersen, 2005). Another important consideration is that I run the risk of being so enthusiastic about my political and theoretical ideals, I will allow this to shape the evidence to support already supposed observations (Lenzo, 1995). That is, I will see what I believe. I also wonder about the "taken-for-granted" aspect of reflexivity in current qualitative research - can you inscribe reflexivity where there is no intention/capacity/valuing of self-reflection? How does one know? Certainly, in my discipline, I could not submit a successful dissertation without attending to reflexivity. Would I want to?

From a positivist perspective, this self-questioning reflection is completely irrelevant. Is it possible that this static and unwavering view of validity has interfered with the creative development of new and innovative quantitative research designs? In this way, has validity become a tool to police what is "real" science and what is not, rather than ensuring any sort of quality (Aguinaldo, 2004)? Disciplined as I am as a "nurse scientist", at some level I feel a bit flaky sharing a deeply personal story with you. I cannot dismiss a positivist perspective because one of the most beautiful roses in the bouquet that is my family is alive today because of quantitative research (relying heavily on validity and not so much on reflexivity) that has contributed to a knowledge base supporting the increased survival rates of prematurely born infants. I am not antiscience but I do expect, like Le Grange \& Beets (2005), all researchers to critically examine the limitations of their work. Reflecting on this, how can the overall validity of healthcare evidence based solely in quantitative methods be accounted for? Are claims 
of the neutrality of the knowledge generated in this tradition "legitimiz[ing] a morally irresponsible position" (Angen, 2000)?

Many philosophers and researchers advocate a broadening of the definition of validity and often use substitute terms such as trustworthiness, credibility, transferability, confirmability, and others (Munhall, 2007). Yet the traditional view of validity still haunts those who engage in research requiring/requesting self-reflexivity. Perhaps a more explicit focus on epistemological reflexivity, asking questions such as how the data/findings are constructed by our research process (Willig, 2001), rather than relying heavily on self-reflexivity would help us find some common ground. As a result, epistemological reflexivity persuades me to reflect upon my assumptions (about the world, about knowledge) that I have made during the research process (Willig, 2001). Whether these assumptions are explicit/implicit and/or both and/or deliberate/ inadvertent and/or both, questioning them will assist me in thinking about the implications of these assumptions in regards to my research, the findings (evidence?) and patients. But this still does not seem to explicitly address the issues of politics and ethics.

Many contemporary non-quantitative articles that address validity refer to Lather's transgressive validity (e.g., Fox, 2003). Lather (1994) first coined this phrase in order to both push the boundaries of the possibilities for validity and position validity as an "incitement to discourse" (cited in Lenzo, 1995). Lather describes her conceptualization of validity as "a dispersion, circulation and proliferation of counter-practices of authority" (p. 40) in which reflexivity, ethics and politics are integral. This moves validity away from dictating the nature of research and towards questioning/ interrogating/challenging the authority of those relying on traditional views of validity as well as opening discussions about what constitutes valid research (Lather, 1994; Lenzo, 1995). This demands the researcher to be present and accounted for in research findings and evidence put forth as new knowledge.

Transgressive validity has since been taken up in a multitude of ways and continues to evolve and grow (e.g. Fox, 2003; Freeman et al., 2007; Lenzo, 1995). To me, Lather's reconceptualizations of validity offer hope: That there are multiple credible sources to draw from and I have choices when reflecting on the validity of my work and what that means when I offer it to my colleagues. In addition, this supports my intention to question the ethics and the politics of contemporary knowledge produced through a perspective drawing heavily on traditional conceptualizations of validity "whereas previously, such claims could have slipped silently and quietly into the realm of valid knowledge" (Aguinaldo, 2004).

The Theory and Practice of Oligarchical Collectivism (1984 State Manual):

The masses never revolt of their own accord, and then never revolt merely because they are oppressed. Indeed, so long as they are not permitted to have standards of comparison they never even become aware that they are oppressed. (George Orwell, 1949/1990)

Although Scheurich (1996) also sees potential in Lather's (1994) transgressive validity, he concludes that validity, by any other name, is still merely a "mask" that conceals an underlying sameness - that of the western philosophical propensity to create dualisms. 
Thus, validity practices construct a particular reality and then replicate a domination of one (Scheurich, 1996). In this way, does self-reflexivity become the vehicle of validity to inscribe the duality of the same/other (and valid/invalid)? Interpretive researchers are also concerned with how self-reflexivity can distance the researcher from "the other" and perpetuate the issue mentioned above (Angen, 2000). The importance of reflexivity is not being disputed; however, it is not the answer to achieving a perspective that allows the researcher to "more fully address the topic" but instead provides insight into "the intersubjective creation of meaning and understanding" (Angen, 2000, p. 383).

In the end, how are these reconciled? Is the point to come to "the answer"? Competing and/or/both/neither complementary views of validity and reflexivity often stem from divergent worldviews. My goal is not to come to any clear answer but rests in the need to resist accepting what is or is not valid research while at the same time, keeping an open debate about how to assess quality, rigour, and robustness. Complexity theory, itself, offers the promise of continued conversation as it "unsettles the easy relationship between science, reason and representation" (Trueit, 2008, p. 25). For me, the main point is that if I ever came to a place of unquestioning acceptance of particular and seemingly transparent definitions of what validity and reflexivity represent, then this conversation stops. And, most importantly, what are the implications of that?

What's in a name? that which we call a rose

By any other name would smell as sweet;

So Romeo would, were he not Romeo call'd,

Retain that dear perfection which he owes

Without that title. Romeo, doff thy name,

And for that name which is no part of thee

Take all myself. (Shakespeare, 1594)

Acknowledgements

The author gratefully acknowledges Drs. Bill Doll and Donna Trueit for their ability to create a "third space" in the classroom and Dr. Carol Picard for her inspiration to use non-traditional sources of patient perspectives, including rap songs, when thinking about nursing practice.

\section{References}

Aguinaldo, J. 2004. Rethinking validity in qualitative research from a social constructionist perspective: From "is this valid research?" to "what is this research valid for?" The qualitative Report, 9(1): 127-136. Retrieved March 17, 2009 from the World Wide Web at: http://www.nova.edu/ssss/QR/QR9-1/aguinaldo.pdf

Angen, M. J. 2000. Evaluating interpretive inquiry: Reviewing the validity debate and opening dialogue. Qualitative Health Research, 10(3): 378-395.

Burns, D. \& Walker, M. 2005. Feminist methodologies. In B. Somekh \& C. Lewin (Eds.) Research methods for the social sciences, pp. 66-73. SAGE: Thousand Oaks.

Cheek, J. \& Gough, N. 2005. Postmodernist perspectives. In B. Somekh \& C. Lewin (Eds.) Research methods for the social sciences, pp. 302-309. SAGE: Thousand Oaks. 
Doll, W. 2008. Chaos and complexity theory. In L. Given (Ed.) The SAGE Encyclopedia of Qualitative Research Methods, p. 74-78. Thousand Oaks, CA: Sage Publications.

Fox, N.J. 2003. Practice-based evidence: towards collaborative and transgressive research. Sociology, 37(1): 81-102.

Freeman, M., de Marrais, K., Preissie, J., Roulston, K. \& St. Pierre, E. 2007. Standards of evidence in qualitative research: An incitement to discourse. Educational Researcher, 36(1): 25-32.

Gillen, J. \& Peterson, A. 2005. Discourse analysis. In B. Somekh \& C. Lewin (Eds.) Research methods for the social sciences, pp. 146-154. SAGE: Thousand Oaks.

Jackson, W. \& Gillis, A. 2002. Research for nurses: Methods and interpretation. Philadelphia: F. A. Davis Company.

Lather, P. 1994. Fertile Obsession: Validity after poststructuralism. In A. Gitlin (Ed.) Power and method: Political activism and educational research, pp. 36-60. Routledge: New York.

Lather, P. 2001. Postmodernism, post-structuralism and post (critical)ethnography. In Atkinson P, Coffey A, Delamont S, et al. (Eds.) Handbook of ethnography (pp. 477-492). Thousand Oaks: Sage Publications.

Le Grange, L. \& Beets, P. 2005. (Re)conceptualizing validity in (outcome-based) assessment. South African Journal of Education, 25(2): 115-119.

Lenzo, K. 1995. Validity and self-reflexivity meet poststructuralism: Scientific ethos and the transgressive self. Educational Researcher, 24(4): 17-23.

Mahoney, J. \& Goertz, G. 2004. A tale of two cultures: Contrasting qualitative and quantitative research. Political Analysis, 14(3): 227-249.

Mautner, T. 2005. Dictionary of Philosophy. Toronto: Penguin Books.

Munhall, P. 2007. Nursing research: A qualitative perspective (4th Ed.). Boston: Jones and Bartlett publishers.

Nightingale, D. \& Cromby, J. (Eds) 1999. Social constructionist psychology: A critical analysis of theory and practice. Buckingham: Open University Press.

Orwell, G. 1949/1990. 1984: A novel. Signet Classic: New York.

Oxford English Dictionary Online. 2009. http://dictionary.oed.com.

Rodgers, B. L. 2005. Developing nursing knowledge: Philosophical traditions and influences. Philadelphia: Lippincott, Williams \& Wilkins.

Rothman, K., Greenland, S. \& Lash, T. 2008. Modern Epidemiology (3rd Ed.). Lippincott Williams \& Wilkins: New York.

Salkind, N. L. 2004. Statistics for people who (think they) hate statistics, 2nd Ed. SAGE Publications: Thousand Oaks.

Scheurich, J. 1996. The masks of validity: a deconstructive investigation. Qualitative Studies in Education, 9(1): 49-60.

Shakespeare, W. 1594. Romeo and Juliet. Retrieved March 26, 2009 from the World Wide Web at: http://www.phrases.org.uk/meanings/305250.html

Shojania, K., Duncan, B., McDonald, K. \& Wachter, R. 2001. Care Safer: A Critical Analysis of Patient Safety Practices. Evidence Report/Technology Assessment: Number 43. Retrieved May 25, 2008 from the World Wide Web at: http://www.ahrq.gov/clinic/ptsafety/

Somekh, B. \& Lewin, C. (Eds.) 2005. Research methods for the social sciences. SAGE: Thousand Oaks.

Stronach, I. \& MacLure, M. 1997. Educational research undone: The postmodern embrace. Open University Press: Philadelphia.

Trueit, D. 2008. Beyond simple order: Complexity and postmodern politics. Journal of the Canadian Association for Curriculum Studies, 6(1): 25-43.

Willig, C. 2001 Introducing Qualitative Research in Psychology: Adventures in Theory and Method. Open University Press: Philadelphia. 
West, K. 2005. Roses [excerpt]. Retrieved March 25, 2009 from the World Wide Web at: http://music.yahoo.com/Kanye-West/Roses/lyrics/23369647

Whittemore, R., Chase, S., \& Mandle, C. 2001. Validity in qualitative researcher. Qualitative Research, 11(4): 522-537.

\section{About the Author}

Lorelei Newton is a doctoral candidate, registered nurse and researcher at the University of Victoria (Canada). Her research includes program evaluation in a hospital setting. Her email address is: lorelei@uvic.ca

(c) Copyright 2009. The author, LORELEI NEWTON, assigns to the University of Alberta and other educational and non-profit institutions a non-exclusive license to use this document for personal use and in courses of instruction provided that the article is used in full and this copyright statement is reproduced. The author also grants a non-exclusive license to the University of Alberta to publish this document in full on the World Wide Web, and for the document to be published on mirrors on the World Wide Web. Any other usage is prohibited without the express permission of the author. 